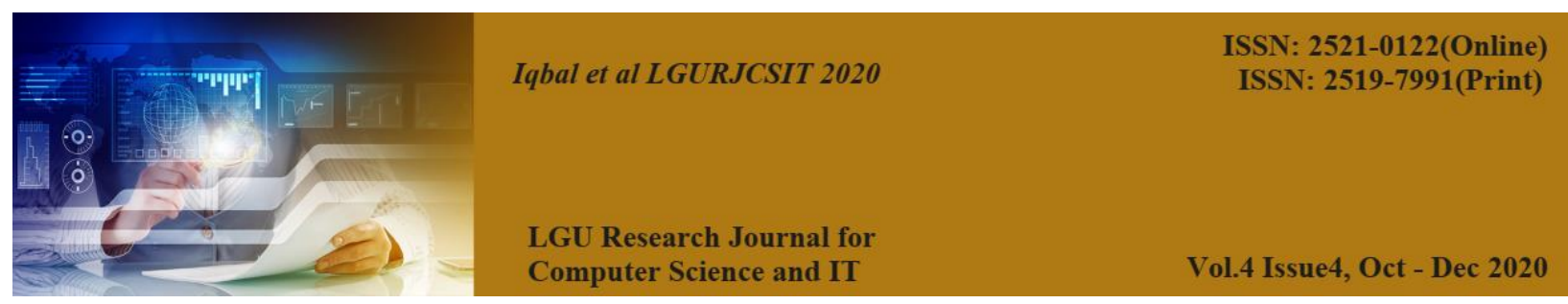

\title{
Usability Evaluation of Online Educational Applications in COVID-19
}

\author{
Muhammad Saeed Ahmad ${ }^{1}$, Muhammad Waseem Iqbal' ${ }^{2}$, Maham Abid ${ }^{3}$, \\ Nadia Tabassum ${ }^{4}$, Syed Khuram Shahzad ${ }^{5}$, Natash Ali Mian ${ }^{6}$, Muhammad Raza Naqvi ${ }^{7}$ \\ ${ }^{1,3}$ Department of Information Technology ,The Superior College,Lahore, Pakistan \\ ${ }^{2}$ Department of Software Engineering,The Superior College,Lahore, Pakistan \\ ${ }^{4}$ Department of Computer Science, Virtual Universiy of Pakistan \\ ${ }^{5}$ Department of Informatics \& Systems, University of Management and Technology, Lahore, Pakistan \\ ${ }^{6}$ School of Computer and Information Technology, Beaconhouse National University,Lahore, Pakistan \\ ${ }^{7}$ Department of Computer Science, The Superior College, Lahore, Pakistan \\ Waseem.iqbal@superior.edu.pk.
}

\begin{abstract}
:
COVID-19 is a pandemic faced by almost every country in the world, this has resulted in health crisis. Due to COVID-19, all the countries around the world have decided to close all educational institutes to prevent this pandemic. Educational institutes have taken every possible measure to minimize the impact of the closure of schools and introduce the concept of an online education system which is not only a massive shock for parents but it also affects the children's learning process and social life. The educational applications (Apps) are very important, because they offer more opportunities for development and growth to society. In this pandemic situation, educational Apps like Zoom, HEC LMS, Google Classroom, and Skype, etc. are the need of the hour when everything goes online. In this paper, the usability features of online educational Apps are thoroughly discussed including the effectiveness and usability for students. Using the results obtained from the survey, this paper observes the student's perspective of usefulness of online educational Apps in student's learning process of different age groups. It also analyzes the easiness for students to understand, interact and use these Apps.
\end{abstract}

Keywords: Usability, Educational apps, User satisfaction, User experience

\section{INTRODUCTION}

Due to COVID-19, all the countries around the world have announced the travel bans,

closure of educational institutes, workplaces, and other places with large public gatherings 
to prevent this disease. Public health officers are taking different precautionary measures like quarantine or self-isolation which means fewer social gatherings and medical officers are also providing information for strengthening the health facilities to prevent this epidemic to control the disease, and asking people to work from home [1]. From 25 March, all the countries around the world have closed educational institutes due to which $80 \%$ of the student population is facing a problem [2]. As academic institutions close across the country, and we all know that Pakistan has already a weak educational infrastructure and the closure of educational institutes is another big challenge for Pakistan [3]. Educational institutes are taking every precautionary measure to prevent this spread of the disease for the safety of their students and faculty members. To prevent the spread of this epidemic faculty members are also taking measures and they are introducing the concept of online education [4].

Mobile Apps can change our lives in several ways, the way we learn, the way we teach due to the virtual environment created to make access to learning objects, such as digital books, tutorials, learning multimedia contents easier [5]. This provides several new ways for students to learn which is not possible in the traditional education system. The educational Apps like Zoom, HEC LMS, Google Classroom, and Skype, etc. are most important, because they offer more significant opportunities for development and growth to society. In Quarantine situations, these applications are most helpful for educational sector [6]. In this context, usability becomes a key factor for its adoption [7]. The objective of this paper is to identify the usability evaluation of mobile educational applications during this pandemic situation which means that how this pandemic situation affects the education system and to determine that the effectiveness of online education. The usability characteristic is defined as "the capability of any software to be understood, learned, used, and attractive for the user", when used under specified conditions [8].

This study aims to analyze the effectiveness, and learnability of the online educational Apps and to find how much the users are satisfied with the usability of mobile educational applications. The effectiveness is calculated by considering that how much time is taken to complete a specific task and satisfaction is measured by using the After Scenario Questionnaire Technique (ASQ) [9]. In this pandemic situation, educational apps like Zoom, HEC LMS, Google Classroom, and Skype, etc. is the need of the hour when everything goes online. We thoroughly discuss the usability features of online educational Apps [10]. Using the results obtained from the survey, this paper observed the student's perspective of usefulness of online educational Apps in student's learning process of different age groups. Further, how much difficult or how much easy it is for students to understand, interact and use these applications. This evaluation also shows up how much online educational Apps provide theoretical and practical experience.

Thus, the main aim of this paper is to answer the following questions:

1) To investigate that the online educational Apps user interface is usable for students or not.

2) To what extent students can understand and use mobile educational Apps.

3) To what extent student can efficiently use the mobile educational Apps.

4) To enhance the usability of online educational Apps. 
The rest of the paper is organized as follows. Section2, describes the background and literature review. Section3 presents the research methodology while section4 states the results and discussion. At the end, conclusion of the study and future work is presented.

\section{BACKGROUND LITERATURE REVIEW}

AND

Most people use the products and applications that are easy to understand, easy to use, and meet their expectations and needs. In the context of the system development process, usability plays a very important and crucial role in achieving user satisfaction or to meet the demands of the users. Usability is the capacity of software which represents that how well a user can use that software and its interface is how much interactive or user friendly [11]. The common qualities of usability that aims to analyze the ease of use of any software are efficiency, effectiveness, user satisfaction, and learnability [12]. The term usability was first used in the 1980s whose aim is to give instructions to software developer about the development of Apps which are user friendly. While developing software the thinking of a developer is that the software is made for humans, as the developer himself is a human so it is assumed that if the developer can use it, everyone can use it. This is the biggest mistake of a developer because he only knows that how to design that system and how it works but the important questions like is that system usable or not, does the system meets the requirements of the user of not, and is the system is user friendly or not are usually not taken into consideration [13].

There is a need to incorporate the users while designing the system because the user has to perform the task. In order to develop good software and to meet the demand of the user, usability testing is required. The questions mentioned in introduction section can only be resolved by using the usercentric design approach and by involving students while developing the system [14]. Summer and Watt adopted two different approaches: i) Mobile applications are created and tested by students; and ii) Existing products are modified by students using instructions/documentation instead of creating a new one. The Results achieved from both the approaches successfully and both approaches are recommended by them as both are easy to adopt and adapt [15]. Alelaiwi and Hossain in have conducted a practical study on the usability evaluation of specific e-learning tools. They divided the user into two groups, one group includes the users who have Human Computer Interaction (HCI) knowledge and the other group includes the users without $\mathrm{HCI}$ knowledge [16]. Usability evaluation questionnaires were distributed to both groups. They concluded in their paper that the group which includes the user without HCI knowledge was more satisfied than the group with users of HCI knowledge because the HCI knowledge group has more expectations with the e-learning tool. UserCentered Design (UCD) is a technique that focuses on increasing usability by reducing the cost of the software [17]. The main difference between other design principles is that UCD tries to improve usability and also consider user satisfaction as a priority [18]. By using the UCD, in 2014 Ahmed discusses the effects of usability of online mobile applications for deaf and illiterate people. The usability scale of the assistance system identifies that the average score of the usability increases from 39 to 80 . The enhanced usability interface offers better to deaf and illiterate people by translating the content in the language that is easily understood by them [19]. 
R. Bernhaupt has categorized different Usability Evaluation (UE) methods [20] that are user testing, inspection-oriented methods (like heuristic evaluation), analytical modeling, and self-reporting and inquiryoriented methods (like questionnaires and interviews). Ivory has also mentioned these methods of usability evaluation in his research [21]. Raptis et al measure how the size of the screen has an impact on the user's efficiency, ease of use, and effectiveness by using the System Usability scale [22]. All the studies mentioned above focus on the methods of usability evaluation of different mobile educational Apps but these methods are not taking the user perspective of usability into consideration which means that how much these apps are usable for students is missing [23]. Thus, the need of the hour is to consider the student's perspective while studying the usability of mobile educational Apps. In this paper, we are examining the usability of mobile educational Apps that how much these Apps are useful for the students or to what extend these are helping the students in learning [24-26].

\section{METHODOLOGY}

A questionnaire was prepared to evaluate some of the most commonly used online educational applications in this pandemic situation. For this purpose, a questionnaire is used for the development and validation of a survey that measures the acceptance and awareness of the user about different online educational applications like zoom, Google classroom, Skype, HEC LMS, and others. The total number of participants included in this survey were 1007 and they belong to different institutes (colleges and universities). Our main focus is on the student perspective that how much students are satisfied with the online education system. In the first part of this paper, the objective and importance of online mobile educational Apps are discussed. The methodology and survey in which different questions are asked related to online education is discussed in second part of this paper. The questionnaire includes some general demographic information in which the user is asked about his/her gender, age, education level, institute, and area of specialization. The questionnaire also includes questions related to online education Apps like:

1. Which online education mobile application is used by your organization?

2. How much online education is beneficial to you?

3. Is online education providing the right amount of information to the student or not?

4. How many students are satisfied with online education?

5. Which online education application is mostly preferred by students?

6. To investigate that the online educational Apps user interface is usable for students or not?

To answer all the above questions a survey of 1007 users is conducted to judge the perspective of the students about online education. Further, the participators have been asked about their willingness to use online mobile educational Apps for learning purpose. The main purpose of this survey is to investigate that the student's satisfaction with the online education system.

\section{RESULTS AND DISCUSSION}

Based on the survey and questions regarding the acceptance and awareness of online educational applications, the learners' responses are analyzed and evaluated. The survey provided a systematic review of the learners, awareness and acceptance of online educational Apps into higher education by assessing and analyzing user demographic 
background and online educational experiences. The responses were collected online through questionnaire and different questions related to online learning were asked. The discussion phase aimed to improve the learners' knowledge and understanding concerning the mobile/online learning context. Based on the overall results of the empirical study, it was discovered that only $36.6 \%$ of participators were agreed that the online education system provides the right amount of information. The results and discussions are further divided into the following subsections:

\section{A. Demographic Background}

The participator is first asked about his/her gender to find out the usage intensity of online educational Apps. The Figure.1 shows that about $55 \%$ of 1007 participators are males and $45 \%$ females are using the online educational Apps.

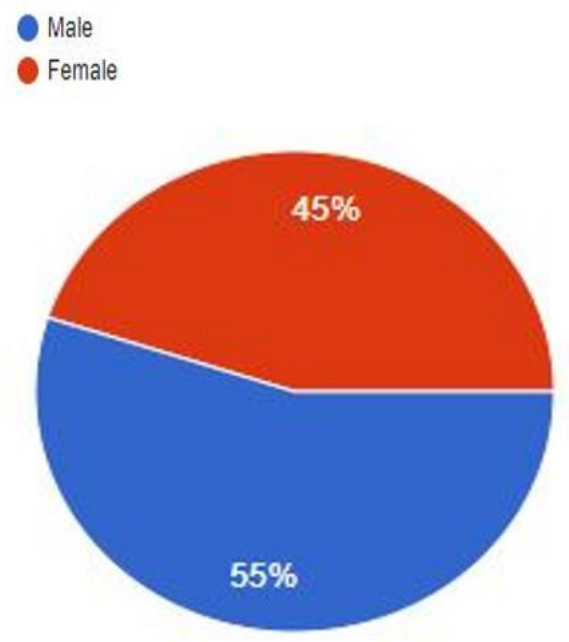

Figure 1: Gender Distribution

The participators of this survey belong to different age groups and are divided from 18 years to 43 years. The analysis is formed by observing the online responses by the participators divided into different age groups. It is observed that the highest number of participators with about 79\% belongs from the age group of 18-24 years old and the lowest number of participators are from the age group of $37-43$ years. It is clear from the above statistics that most of the young people are using the online educational Apps. The Figure. 2 shows the age distribution of the participators.

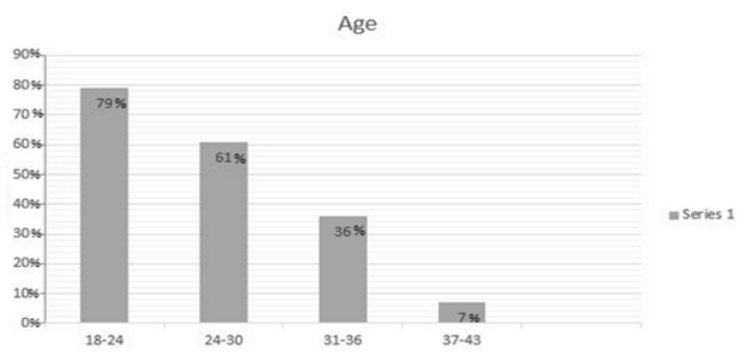

Figure 2: Age Distribution

The Figure.3 shows the educational distribution of the participators. The result is shown that the highest percentage of the participants with $83 \%$ are using online education applications studies in higher education. Whereas rest were distributed between intermediate $9 \%$, secondary school $11 \%$, and others $7 \%$.

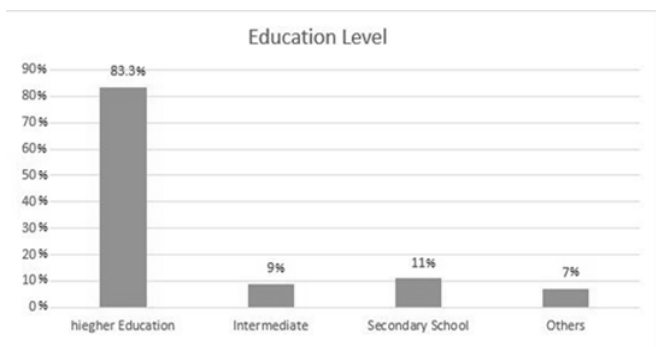

Figure 3: Education Level Distribution

\section{B. Educational application:}

In this part of survey, it is investigated that which online educational application or learning management system (LMS) is primarily used by the students or organizations. By viewing the Figure.4, it is observed that $42.3 \%$ of the participators are using the zoom application for online education. The rest were distributed between HEC LMS which is $20.8 \%$, Google classroom $16.1 \%$, and a very little number 
of participators were using skype. Moreover, the online Apps for other systems is $19.3 \%$.

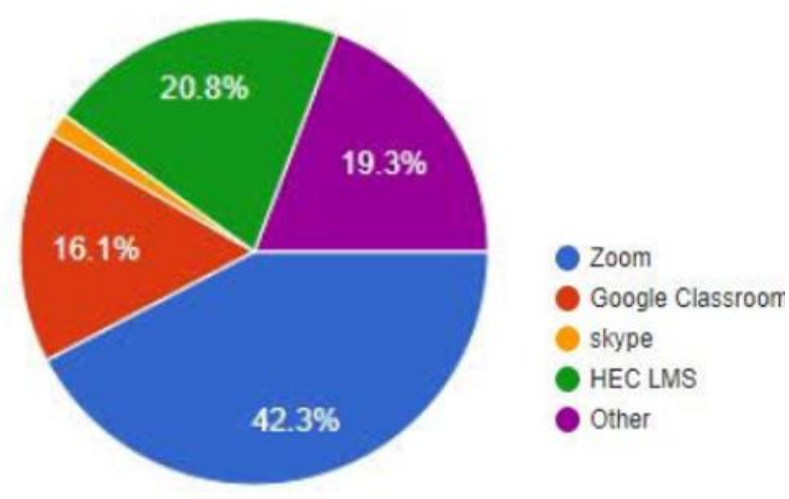

Figure 4: Different Educational Apps

\section{Online education experience:}

The online education experience is shown in Figure.5 in this part of survey. The participators understanding and experience related to online educational applications was investigated. In this regard, $50.7 \%$ of the participators have experienced of using online educational application or they know how to use these Apps while the remaining $49.3 \%$ do not have experience of using the online educational Apps.
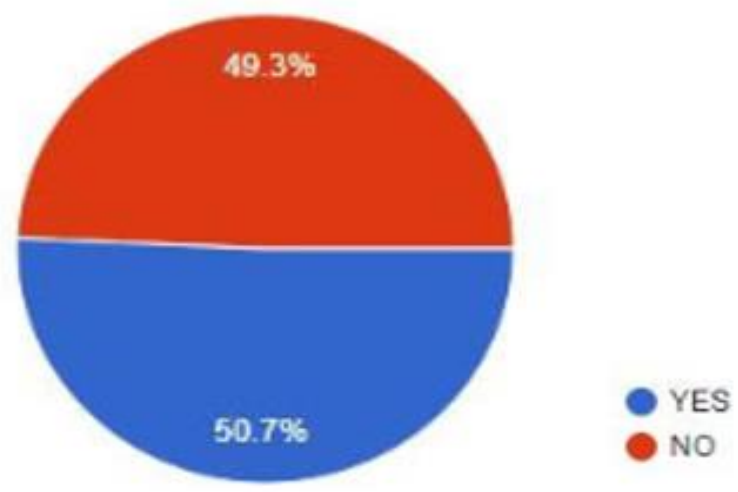

Figure 5: User Experience

\section{Information delivery experience:}

In this part of survey, it is investigated that online education applications provided the right amount of information delivery experience to users. It is observed that online education does not provide the right/exact amount of information to the users. The statistics shown in Figure. 6 are elaborated that only $36.6 \%$ of the participators think that the online education application is providing the right information to the users while the remaining $63.4 \%$ of the participators are not satisfied.

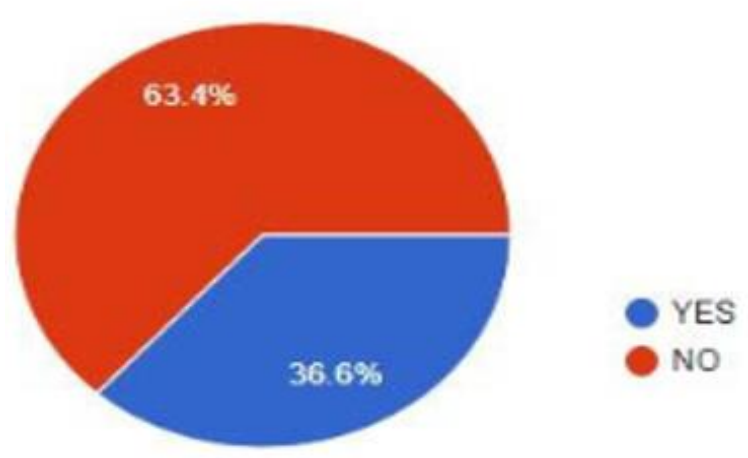

Figure 6: User Experience for Information Delivery

\section{E. Satisfaction level:}

The participators were asked how satisfied they are with online education system and their willingness to adopt the online education system. In this part the satisfaction level of the participants is divided into four sections: poor, moderate, good, and excellent. In Figure.7, the results taken from survey are shown that only $10.6 \%$ participators are fully satisfied by online education system. The results for good $(23.6 \%)$, poor $(25.3 \%)$, and moderate $(40.4 \%)$ users are also shown respectively. 


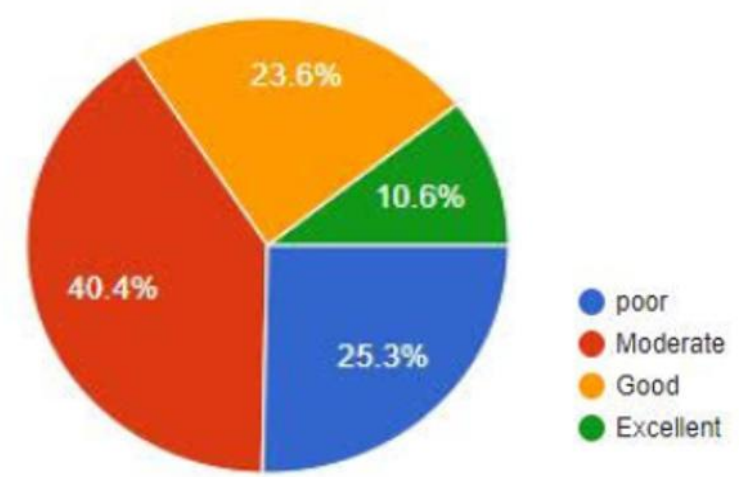

Figure 7: User Satisfaction Level

\section{CONCLUSION}

In this paper, we have discussed the usability evaluation of educational applications in COVID-19. The survey was conducted for educational Apps and the users were students of different institutions. We have evaluated the user experience and satisfaction level for online Apps in pandemic. There were 1007 participants where male's percentage was 55 and female's percentage was 45 . It is observed that the higher education sector is excessive user of online applications with $83 \%$. The usage of different educational applications is measured for Zoom $=42 \%, \quad \mathrm{LMS}=21 \%$, others $=19 \%$, Google classroom $=16 \%$, and Skype-2\%. It is also found that $50.7 \%$ users experienced online educational Apps during this pandemic. Further, most of the users are not consumed good information delivery experience which is $63.4 \%$. Similarly, the satisfaction of users is a significant part during online education using Apps. It is concluded that only $10.6 \%$ users are found satisfied while $25.3 \%$ are poor in satisfaction. Furthermore, it is illustrated that overall users are moderated satisfied by using online educational Apps during pandemic.

\section{References}

[1] Bedford J, Enria D, Giesecke J, et al.: COVID19: towards controlling of a pandemic. Lancet. 2020.

[2] UNESCO. COVID-19 Educational disruption and response. (2020). Accessed: March 25, 2020: https://en.unesco.org/themes/educationemergencies/coronavirus-school-closures.

[3] Ericsson Mobility Report: On the Pulse of the Networked Society, Ericsson, Stockholm, Sweden, Nov. 2013.

[4] Jacob, S. M., \& Issac, B, Mobile technologies and its impact: An analysis. In: Higher education context. In: International journal of Interactive Mobile Technologies, 2008, p. 2-10.

[5] J. I. R. Molano, E. S. Yara and L. K. J. García, "Model for measuring usability of survey mobile apps, by analysis of usability evaluation methods and attributes," 2015 10th Iberian Conference on Information Systems and Technologies (CISTI), Aveiro, 2015, pp. 1-6.

[6] Nielsen, J.,. "How to Conduct a Heuristic Evaluation".2000 http://www.useit.com/papers/heuristic/heuris tic_evaluation.html [12/02/2007].

[7] C. X. Navarro, A. I. Molina, M. A. Redondo and R. Juárez-Ramírez, "Framework to Evaluate MLearning Systems: A Technological and Pedagogical Approach," in IEEE Revista Iberoamericana de Tecnologias del Aprendizaje, vol. 11, no. 1, pp. 33-40, Feb. 2016.

[8] Zhang, D, \& Adipat, B. (2005). Challenges, methodologies, and issues in the usability testing of mobile applications. International Journal of Human-Computer Interaction, 18(3), 293-308, 2005.

[9] J. I. R. Molano, E. S. Yara and L. K. J. García, "Model for measuring usability of survey mobile apps, by analysis of usability evaluation methods and attributes," 2015 10th Iberian Conference on Information Systems and Technologies (CISTI), Aveiro, 2015, pp. 1-6.

[10] Wesson, J. L., Singh, A., \& Van Tonder, B. Can adaptive interfaces improve the usability of mobile applications? In Human-ComputerInteraction. Springer Berlin Heidelberg. 2010. p. 187-198.

[11] S. V. Cáceres and J. A. Pow-Sang, "A systematic mapping review of usability evaluation methods for educational applications on mobile devices," 2018 7th International Conference On Software Process Improvement (CIMPS), Guadalajara, Jalisco, Mexico, 2018, pp. 59-68. 
[12] P. Hung, J. Lam, C. Wong and T. Chan, "A Study on Using Learning Management System with Mobile App," 2015 International Symposium on Educational Technology (ISET), Wuhan, 2015, pp. 168-172.

[13] Kahn, J. S., \& McIntosh, K. (2005). History and recent advances in coronavirus discovery. The Pediatric infectious disease journal, 24(11), S223-S227.

[14] H. Rahmat, H. Zulzalil, A. A. Abd Ghani and A. Kamaruddin, "An approach towards development of evaluation framework for usability of smartphone applications," 2015 9th Malaysian Software Engineering Conference (MySEC), Kuala Lumpur, 2015, pp. 178-182.

[15] Summers, S., Watt, A.: Quick and dirty usability testing in the technical communication classroom. In: Professional Communication Conference (IPCC), 2015 IEEE International, pp. 1-4. IEEE (2015).

[16] Alelaiwi, A., Hossain, M.S.: Evaluating and testing user interfaces for e-learning system: blackboard usability testing. J. Inf. Eng. Appl. 5(1), 23-30 (2015).

[17]D. McDonagh and J. Thomas. Disability relevant design: Empathic design strategies supporting more effective new product design outcomes. The Design Journal 13(2), pp. 180-198. 2010.

[18] Anthony, L., Brown, Q., Nias, J., Tate, B., \& Mohan, S. Interaction and recognition challenges in interpreting children's touch and gesture input on mobile devices. In Proceedings of the ACM international conference on Interactive tabletops and surfaces. 2012. p. 225-234.

[19] Ahmad, N. People Centered HMI's for Deaf and Functionally Illiterate Users. Doctoral dissertation. Politecnico di Torino-Universität Potsdam, Germany. 2014.

[20] Iqbal, M. W., Ahmad, N., Shahzad, S. K., Naqvi, M. R., \& Feroz, I. (2018). Usability Aspects of Adaptive Mobile Interfaces for Colour-Blind and Vision Deficient Users. INTERNATIONAL JOURNAL OF COMPUTER SCIENCE AND
NETWORK SECURITY, 18(10), 179189.Melody Yvette Ivory, “An Empirical Foundation for Automated Web Interface Evaluation ",2001.

[21] Raptis, D., Tselios, N., Kjeldskov, J., Skov, M.B.: Does size matter?: investigating the impact of mobile phone screen size on users' perceived usability, effectiveness and efficiency. In: Proceedings of the 15th International Conference on Human-Computer Interaction with Mobile Devices and Services, pp. 127-136. ACM (2013)

[22] A. Veldsman and D. van Greunen, "Comparative usability evaluation of a mobile health app," 2017 IST-Africa Week Conference (IST-Africa), Windhoek, 2017, pp. 1-8.

[23] H. Rahmat, H. Zulzalil, A. A. Abd Ghani and A. Kamaruddin, "An approach towards development of evaluation framework for usability of smartphone applications," 2015 9th Malaysian Software Engineering Conference (MySEC), Kuala Lumpur, 2015, pp. 178-182.

[24]Zhang, D, \& Adipat, B. (2005). Challenges, methodologies, and issues in the usability testing of mobile applications. International Journal of Human-Computer Interaction, 18(3), 293-308, 2005.

[25]Zapata, Belén \& Fernández-Alemán, José \& Idri, Ali \& Toval, Ambrosio. (2015). Empirical Studies on Usability of mHealth Apps: A Systematic Literature Review. Journal of medical systems. 39. 182. 10.1007/s10916-0140182-2.

[26] M. R. Naqvi, S. K. Shahzad, M. W. Iqbal, M. Ahmed, M. U. Tahir and B. A. Khan, "Need for Computational and Psycho-linguistics Models in Natural Language Processing for Web Documents," 2020 4th International Symposium on Multidisciplinary Studies and Innovative Technologies (ISMSIT), Istanbul, Turkey, 2020, pp. 1-5, doi: 10.1109/ISMSIT50672.2020.9254754.

\section{Annexure-A}

The questionnaire is attached. 
Survey: Analysis and Usability Evaluation of Educational Apps in Pandemic COVID-19

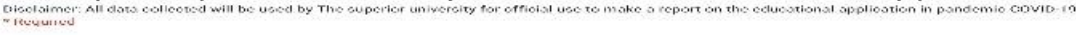

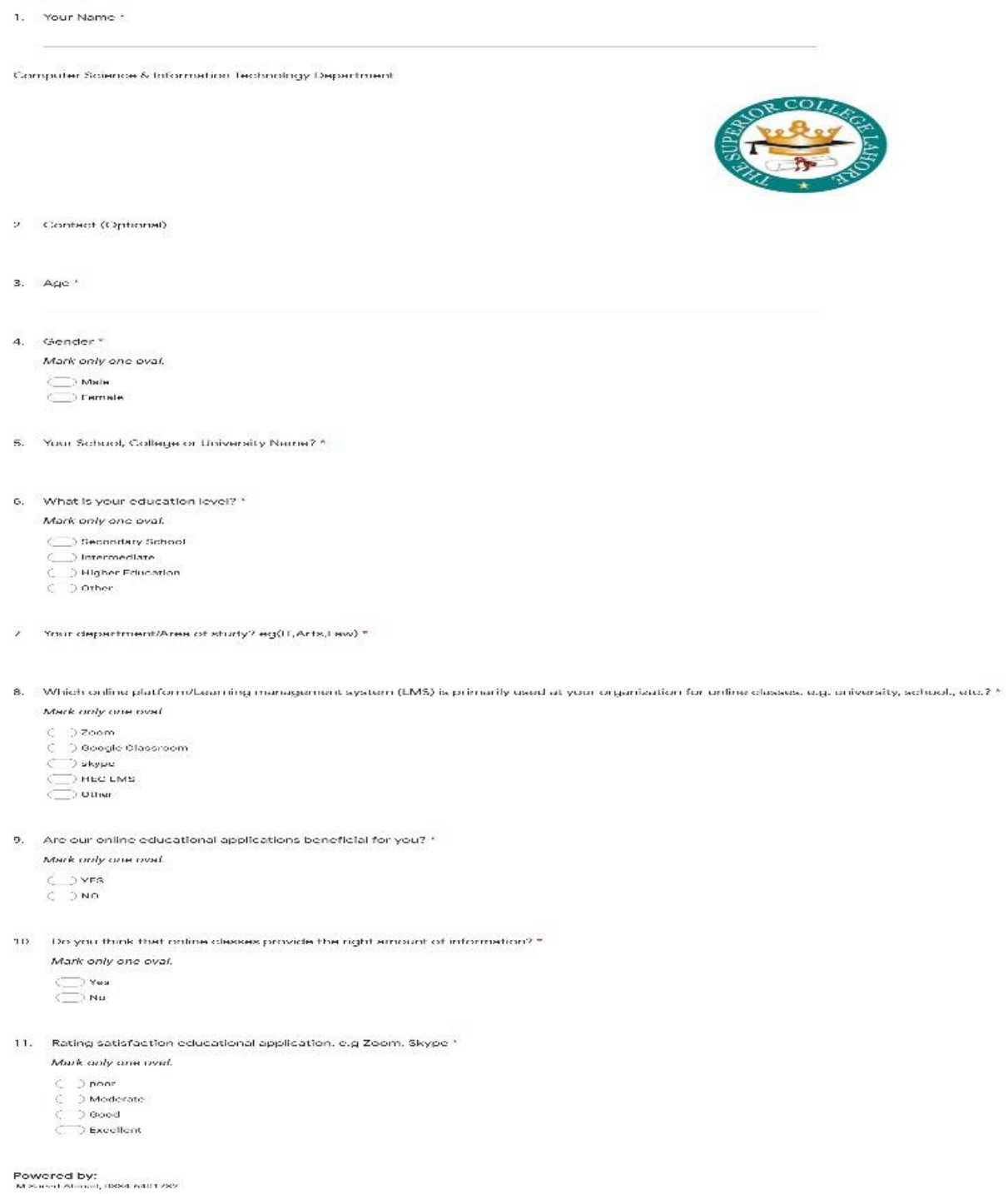

